\title{
Materialidades culturales y mediaciones narrativas hipermediales en educación a distancia ${ }^{1}$
}

María Alejandra Ambrosino

FHUC-UNL

\section{Resumen}

El presente artículo se propone reflexionar sobre una dimensión de la educación mediada por tecnologías y sus diferentes formas de representación en un modo curricular específico como es el de la educación a disPalabras clave: narrativas, hipermediaciones, cultura, enseñanza, virtualidad. tancia. Más allá del modo de representación tecnológico interesa abordar la perspectiva cultural a partir de sus diferentes mediaciones narrativas. Para ello vamos a definir la idea de las materialidades culturales desde su operacionalidad y cómo su forma contempla determinadas posibilidades en la educación a distancia a partir de las mediaciones narrativas virtuales.

Este ensayo intenta reflexionar sobre cultura, educación y entornos digitales con una mirada retrospectiva

1. Este artículo fue escrito en el marco de las investigaciones realizadas por la autora como maestranda de la carrera de Especialización y Maestría en Tecnología de la UBA. Y a partir del trabajo de campo realizado en el contexto del Programa de Educación a Distancia de la UNL. 
sobre los materiales didácticos y a la vez proyectiva sobre la enseñanza en entornos digitales.

\section{Abstract \\ Cultural Materialities and Hypermedia Narrative Mediation in Online Education}

This article intends to reflect on one dimension of education mediated by technology and its different forms of representation in a specific curricular type: online education. Regardless of the type of technoKeywords: narratives, hypermediation, culture, education, teaching, virtuality. logical representation, this work intends to address the cultural perspective that results from its different narratives mediations. In order to do that, the idea of cultural materiality is defined from its operationality, and how its form contemplates certain possibilities in online education based on virtual narrative mediations.

This essay intends to reflect on culture, education and digital environments from a retrospective view on teaching materials, and at the same time a projective view on teaching in digital environments.

\section{Cultura e interfaz: sus} materializaciones y significados

Uno de los conceptos tal vez más definidos en las ciencias sociales es el de cultura, desde allí su dificultad e importancia para reflexionar sobre él. De todas maneras nosotros tomaremos una dimensión del mismo, su materialidad. De las múltiples manifestaciones culturales que podamos conocer comenza- remos a observar que tienen diferentes materialidades como ser una pintura, una fotografía, una escultura, la palabra, una danza, un libro, una casa, los ambientes digitales por mencionar sólo algunas de manifestaciones humanas.

Piscitelli en parte de su obra reflexiona sobre la «materialidad de la cultura», ${ }^{2}$ para analizar los efectos de la irrupción de la dimensión digital en la cultura a través de 